\title{
POLÍTICAS DE INMIGRACIÓN, CIUDADANÍA Y ESTADO DE EXCEPCIÓN
}

\author{
José Antonio Zamora \\ Instituto de Filosofia - CSIC (Madrid)
}

\begin{abstract}
Starting from the contradictions and crisis of citizenship in modern societies, affecting not only the relationship between their universalising logic and the territorial limits of the validity of rights but also those which influence the relationship between the logic of Market an that of human rights, this article analyses the intensification of such contradictions in connection with the phenomenon of immigration. It also explores the links between the forms of a legal, social, economic, political and cultural state of emergency experienced by immigrants and its value as an interpretative key of the undermining of citizenship suffered by a large number of people in the developed societies.
\end{abstract}

KEY WORDS Citizenship, migration, state of emergency, sovereignty, capitalism, mobility, control.
RESUMEN Partiendo de las contradicciones y crisis de la ciudadanía en las sociedades modernas, tanto las que afectan a la relación entre su lógica universalizadora y los límites territoriales de la validez de los derechos, como las que afectan a la relación entre la lógica del mercado y la lógica de los derechos humanos, este artículo analiza la agudización de dichas contracciones en conexión con el fenómeno de la inmigración y explora los vínculos entre las formas de excepcionalidad jurídica, social, económica, política y cultural que viven los inmigrantes y su valor como clave interpretativa de los procesos de socavamiento de la ciudadanía que sufren amplios sectores de población en las sociedades desarrolladas.

PALABRAS CLAVE Ciudadanía, migración, estado de excepción, soberanía, capitalismo, movilidad, control
La mayoría de analistas del fenómeno migratorio suelen llamar la atención sobre una paradoja que resulta significativa. Se trata del contraste entre la creciente liberalización y desregulación de los flujos de capital, mercancias, tecnología e información de la mano de los procesos que se conocen con el nombre de globalización, por un lado, y el reforzamiento de los controles fronterizos y las dificultades selectivas impuestas a la circulación de personas y de fuerza de trabajo, por otro. Mientras las fronteras nacionales, y con ellas las instancias que representan la soberanía de los Estados y los mecanismos que la hacen efectiva, pierden significación voluntariamente en relación con aquellos flujos, asistimos a un aumento del control estatal sobre los movimientos del trabajo a través de legislaciones y políticas migratorias cada vez más duras y restrictivas.

Este comportamiento de los Estados cuestiona uno de los mitos más importantes de la modernidad occidental: el mito de la libertad de movimiento, parte constitutiva de la libertad formal presupuesta por el nuevo tipo de relaciones contractuales que caracteriza el funcionamiento del mercado en las sociedades capitalistas y el orden jurídico-político que lo acompaña. Dicha libertad de movimiento sería la condición de posibilidad del ejercicio efectivo del estatus de ciudadanía que representa la emancipación frente a sujeciones territoriales, laborales y políticas impuestas a los individuos por normativas y poderes coactivos externos. Aquellos que en la "libre" negociación del contrato no posee otra cosa para negociar más que su fuerza de trabajo, han de poder sustraerse a las condiciones ofrecidas por la contraparte gracias a una libertad de movimiento no sujeta a limitación. Por eso, la intensificación y endurecimiento de los controles fronterizos y la creciente dificultad que sufren determinados sectores de población para traspasar las fronteras estatales es un dato de gran importancia a la hora de arrojar una mirada crítica sobre las relaciones que mantienen entre sí los conceptos de soberanía, ciudadanía, contrato, movilidad, etc., tan significativos en el discurso político de la modernidad.

¿Cómo interpretar esa intensificación y ese endurecimiento, sobre todo si tenemos en cuenta su éxito sólo limitado? Podría pensarse que los Estados intentan compensar la desnacionalización de la economía con una renacionalización del ámbito de la política en el que todavía pueden ejercer la soberania nacional, esto es, el control fronterizo del tránsito de personas. Las politicas de inmigración representarian, según esta interpretación, el último bastión de los Estados 
nacionales en descomposición y retirada. Su fracaso, al menos parcial, podria explicarse, de una parte, por la fuerza de los procesos económicos en marcha y la movilidad que imponen a sus factores constitutivos $y$, de otra, por la constricción que sufre la acción de los Estados a causa de los limites relativos que lleva consigo el régimen de derechos humanos, parcialmente operante dentro de ellos (ordenamiento constitucional, firma de convenios internacionales, discursos políticos sobre la legitimidad del gobierno, etc.), y que, junto a las instituciones y convenios internacionales que lo representan y codifican, es convertido por los actores sociales que actúan dentro y fuera de sus límites en una instancia de control (político y jurídico) de las políticas migratorias. El fracaso parcial de estas políticas y la presencia cada vez más relevante en los paises desarrollados de inmigrantes estables, así con el progresivo reconocimiento de un conjunto de derechos tradicionalmente reservados a los nacionales, estaría conduciendo a un replanteamiento de la cuestión de la soberanía y, unida a él, a una transformación de la ciudadanía que, según los más optimistas, terminará liberándola, no sin conflictos y zigzagueos, de sus límites nacionales y permitirá la integración no sólo económica y social, sino también política de los inmigrantes. Los derechos humanos internacionales aparecen en este discurso como una "fuerza que puede socavar la exclusiva autoridad del estado sobre sus naturales y, por lo tanto, contribuir a transformar el sistema interestatal y el orden juridico internacional» (Sassen, 2001, 97). ${ }^{1}$

¿Estamos realmente ante una sustitución de la ciudadanía por la residencia como fuente de los derechos? Si atendemos a las tendencias en curso, resulta al menos aventurado afirmar que caminamos hacia una concepción societaria y postnacional de la ciudadanía. Más bien asistimos a un retroceso general de esa concepción, más llamativo aún en los paises que han mantenido con anterioridad unas políticas migratorias más abiertas, aunque sólo fuera por conveniencia de sus respectivos mercados de trabajo o por sus compromisos postcoloniales. La integración de los inmigrantes se ofrece hoy en los paises desarrollados en forma de una inclusión subordinada y, durante un largo periodo de tiempo, cancelable. Vemos como se produce una proliferación de estatutos de pertenencia y de dosificación de derechos acorde con la fragmentación del mercado de trabajo y la estratificación del goce efectivo de dichos derechos provocada por formas persistentes de discriminación social y administrativa que afectan al conjunto de la población.
Es preciso, pues, atender al comportamiento selectivo que adoptan las fronteras consideradas como mecanismos de inclusión/exclusión, es decir, no sólo como límites territoriales y legales separadores de nacionales y extranjeros, sino como mecanismos más generales de cierre y apertura que actúan sobre todo tipo de flujos (de mercancias, capitales, información, tecnologia, personas, etc.). Frente a la impresión que pretende provocar el discurso político-mediático sobre la globalización, como si ésta hubiese establecido un espacio de intercambio homogéneo y abierto, cabe afirmar que ni el acceso a los recursos, ni la distribución de beneficios, ni la movilidad de la fuerza de trabajo, ni la circulación de mercancías se produce en un régimen de completa libertad y simetría (Foro I. Ellacuría, 1999). En este sentido, la inmigración se ha convertido en un terreno de experimentación de las políticas de gobierno en el que pueden observarse tendencias que apuntan en una dirección opuesta a la señalada más arriba, es decir, "a desmenuzar el universalismo de la ciudadania y a instituir nuevas fronteras dentro de los espacios políticamente homogéneos" (Mazzadra, 2005, 107). En el sistema capitalista la disolución de fronteras y la flexibilización o eliminación de ataduras siempre ha ido de la mano de la proliferación de nuevas fronteras y de nuevos controles de la movilidad destinados a la sujeción de la fuerza de trabajo. En esta dialéctica las fronteras nacionales constituyen un mecanismo de control entre los muchos de que disponen las técnicas de gobierno modernas.

Entre estas técnicas de gobierno merece especial mención la "clandestinización» de los inmigrantes y las sanciones que la acompañan (expulsiones inmediatas, centros de internamiento, condición de alegalidad de los uinexpulsables», etc.). Pese a todas las declaraciones oficiales de lucha contra las entradas ilegales de extranjeros de terceros paises, la condición de irregularidad se ha convertido en una característica estructural de los flujos migratorios actuales. Esto resulta especialmente pertinente si nos referimos al modelo migratorio español, pero se puede extrapolar al conjunto de los paises desarrollados. Dicho modelo es en lo fundamental un sistemas de inmigración irregular (Izquierdo, 2001, 135). De modo objetivo, la clandestinización constituye una forma específica de inclusión del trabajo inmigrante que consigue (y quizás persigue) su máxima vulnerabilidad y, por tanto, la minimización de la capacidad de resistir y contestar las condiciones que impone el capital. Pero, más allá de ella, la temporalidad de los permisos de residencia, su vinculación con los permisos de trabajo, la restricción de estos a territorios y sectores productivos determinados, las crecientes

ARBOR CLXXXI 713 MAYO-JUNIO [2005] 53-66 ISSN: 0210-1963 
dificultades a la reunificación familiar, etc. son otras tantas medidas impuestas a los inmigrantes regularizados que sirven al mismo objetivo. $Y$ no estamos ante defectos de funcionamiento propios de una fase temprana del sistema capitalista, sino ante una combinación de flexibilización y control que ha existido siempre y que realiza una función constitutiva dentro de dicho sistema aquejado permanentemente de la tentación autoritaria. Resulta necesario, pues, analizar desde esta perspectiva las contradicciones y crisis de la ciudadania moderna, el carácter paradigmático que posee la inmigración para comprenderlas y la relación entre excepcionalidad y norma referida a las técnicas de gobierno que afectan a inmigrantes y autóctonos y regulan las formas de inclusión excluyente de importantes sectores de la población.

\section{Contradicciones y crisis de la ciudadanía en el capital-parlamentarismo}

Si nos atenemos a lo esencial del discurso político de la modernidad, no deberían existir otros límites de la comunidad política que la voluntad de los individuos de querer participar en la conformación de la misma y de acatar el pacto realizado por procedimientos legítimos. El demos debería ser una comunidad abierta. ${ }^{2}$ Dado que el Estado democrático es una asociación de individuos libres e iguales, el acuerdo democrático en torno al orden social y político debería bastar para garantizar la lealtad al Estado de derecho y los vínculos asociativos. ${ }^{3}$ La realidad histórica muestra, sin embargo, que en buena medida sin las bases coactivas que aportaban las Naciones-Estado predemocráticas hubiera sido imposible desarrollar las infraestructuras económicas, administrativas y técnico-científicas que caracterizan a los Estados de Derecho modernos. Los Estados democráticos heredan de aquellas, además, la vinculación a un territorio delimitado por fronteras precisas y la definición de la pertenencia al demos en términos no contractuales, sino nacionales. La ficción del "estado de naturaleza", que en el discurso contractualista define la situación previa al contrato social, se revela no como un recurso argumentativo para garantizar la igualdad y libertad efectivas de quienes tienen la voluntad de participar en el pacto, sino como un velo que oculta no sólo, como veremos, las desigualdades "reales" de los socios, sino también la exclusión de quienes no poseen el título de nacionalidad. No es realmente el "hombre natural» el que se puede sentar a la mesa de negociación del contrato politico, sino sólo aquel que es miembro de la nación, y de entrada únicamente el varón nacional con título de propiedad.
La pertenencia a la comunidad politica (demos) estará condicionada, pues, por la pertenencia a una comunidad definida en términos de cultura, historia, lengua o tradiciones compartidas (etnos), es decir, por la pertenencia a una comunidad territorial, lingüistica o cultural portadora de valores y sentido, que posee raíces y crea vínculos poderosos entre sus miembros capaces de sustentar las exigencias más absolutas, como el sacrificio de la propia vida, que enmarca y, en cierto sentido, trasciende la voluntariedad y la absoluta libertad de opción del individuo autónomo al crear identificaciones potentes que superan la mera adhesión a un código legal que regula la libertad y la equidad entre iguales. ${ }^{4}$ De esta manera, el vínculo entre Estado y Nación introduce en el concepto de ciudadanía elementos que el discurso político de la modernidad debería en coherencia rechazar, ya que en su lógica los únicos requisitos para participar en el pacto que constituye la comunidad política serían la libertad y la igualdad naturales, es decir, las que supuestamente posee todo ser humano por el mero hecho de nacer. Pero el Estado-nación sólo reconocerá el estatus de ciudadano a aquellos que posean el título de nacionalidad y sólo estos podrán reclamar de la comunidad política que garantice los derechos que dan contenido al título de ciudadanía, independientemente de los efectos que obtenga dicha reclamación. De esta manera y desde el comienzo, el vínculo entre ciudadanía y nacionalidad establece una incompatibilidad matizable, pero nunca cabalmente superable, entre ciudadanía y extranjeria.

Sin embargo, no es ésta la única limitación que afecta al ejercicio de la ciudadanía. La otra, no menos importante, proviene de lo que podíamos considerar la segunda gran columna que sostiene el edificio de las sociedades modernas, es decir, de la institución del mercado capitalista como mecanismo que regula los intercambios sociales, asi como de los elementos que dicho mecanismo necesita para funcionar: la división social del trabajo, la regulación jurídica de la propiedad privada y el contrato y la inclinación individual a obtener la máxima satisfacción de sus necesidades y el máximo beneficio. Desde la perspectiva del mercado capitalista la igualdad de los individuos que participan en él y establecen relaciones según sus condiciones no es un presupuesto de carácter moral o una exigencia política, sino un requisito imprescindible de funcionamiento. Ahora bien, se trata de una igualdad necesariamente formal, una igualdad en un ámbito discursivo especializado que resulta vital para el funcionamiento del sistema. Dado que las mercancias no pueden intercambiarse por si solas, necesitan de titulares que las conviertan en propiedades adquiribles y enajenables, 
resulta necesario que todas las personas sean representables como propietarios de algo, todos han de ser igualmente propietarios, aun cuando algunos sólo lo sean de su capacidad de trabajo (Capella, 1993, 65ss). Esta igualdad formalmente atribuida por el sistema juridico no impide la desigualdad en todos los demás aspectos de la vida. Se trata de una igualdad necesaria para el intercambio capitalista, cuyo correlato es la libertad entendida como capacidad para comprar y vender, para adquirir o enajenar bienes. Tanto la libertad como la igualdad se atribuyen a todos los ciudadanos a través de una construcción juridica que prescinde de las limitaciones y desigualdades materiales de los individuos reales. Mientras que la igualdad y la libertad jurídicas pertenecen al ámbito de lo público, las coacciones y desigualdades reales son atribuidas al ámbito privado.

En este nuevo marco, el Estado de derecho tiene una doble exigencia: de un lado, garantizar las condiciones de funcionamiento del sistema capitalista y, de otro, administrar el discurso y las reglas de la legitimidad política, que se apoya tanto en argumentos e instrumentos procedimentales y de representación política, como en el recurso que podriamos llamar "mítico» a la comunidad nacional. El conflicto entre ambas exigencias ha tenido diferentes expresiones a lo largo de los dos últimos siglos, desde las luchas sucesivas por alcanzar un verdadero "sufragio universal», es decir, de adecuar el demos a la población, hasta las múltiples reivindicaciones de participación ciudadana frente un sistema de representación política que escamotea la voluntad política de los ciudadanos y la supedita a la lógica y las exigencias del sistema económico capitalista, pasando por la conquista al menos formal de las sucesivas generaciones de derechos (civiles, políticos, sociales y culturales). Pero puede afirmarse sin temor a exagerar que en el capital-parlamentarismo el sistema de representación política, supuesta expresión de la voluntad del demos, nunca hasta ahora se ha impuesto a la lógica del sistema económico capitalista, que, en caso de crisis, ya sea por medio de la innovación tecnológica o el ataque político a las conquistas de los trabajadores, o por ambas cosas, cuando no por medio de la suspensión temporal del orden juridico de libertades formales, ha conseguido supeditar la libertad y la igualdad politicas reales a las exigencias de los procesos de valorización del capital. Lo que hoy denominamos proceso de globalización, el triunfo de las políticas "neoliberales" y la Ilamada crisis del Estado del Bienestar, no hace sino confirmar la tesis de Capella: "es el poder político, hasta ahora el Estado pero ya no solamente el Estado, el que realiza las funciones de conservación de las estructuras de poder extrapolítico que impiden el desarrollo de las tendencias emancipatorias» (Capela, 1993, 91).

Hablar de ciudadanía exige, pues, prestar máxima atención a la involución actual del proceso de democratización politica. Las transformaciones funcionales de los Estados nación en el nuevo (des)orden mundial presidido por la llamada mundialización neoliberal suponen una limitación de los espacios políticos en los que la "soberanía popular" puede hacerse valer frente al poder extrapolítico exponencialmente acumulado gracias a los procesos de liberalización de los mercados trasnacionales de mercancias, tecnologias y capitales. También asistimos a una importante crisis del sistema de representación política, debida entre otras causas a la escasa democracia interna de los partidos políticos, que más que representar la voluntad de los electores, se han convertido en aparatos de ajuste político-económico supeditados a potentes intereses corporativos. La "seguridad", supuestamente de las poblaciones, en realidad de los aparatos de poder, se ha convertido en el recurso más utilizado por la retórica politica para justificar el recorte de libertades y garantías individuales. Las nuevas técnicas de gobierno han asentado la primacia de los poderes ejecutivos sobre los parlamentos, pretendida sede de la voluntad popular. Y los medios de comunicación de masas, junto a la potente industria cultural, no sólo son enormes aparatos al servicio de la mercadotecnia electoral, sino instrumentos eficacísimos de desmovilización política y reproducción del conformismo adaptativo de los ciudadanos (Garcia Inda, 2003a).

Esto nos obliga a revisar el discurso político de la modernidad y su categoria fundamental de "ciudadanía" antes de ponerla en relación con el fenómeno de la inmigración, pues no se trata simplemente de analizar la exclusión de los inmigrantes de un estatus ciudadano no problematizado y proponer sin más una incorporación al mismo, sino de comprender dicha exclusión como un elemento entre otros de las contradicciones que el mismo estatus de ciudadanía sufre en el capital-parlamentarismo (Velasco, 2003, 22). La presencia de los inmigrantes produce en realidad un "efecto espejo" sobre dichas contradicciones (Zapata, $2000,15)$. Este planteamiento permite, a su vez, considerar la reivindicación de la ciudadanía plena para los inmigrantes como un elemento de la lucha por una ciudadanía plena para todos.

Como ha señalado G. Agamben, la proclamación de libertad e igualdad de todos los ciudadanos, que define el marco

ARBOR CLXXXI 713 MAYO-JUNIO [2005] 53-66 ISSN: 0210-1963 
normativo de lo político en la modernidad, representa una entronización de la vida natural como valor absoluto a garantizar frente a la arbitrariedad del poder absoluto del soberano. La política moderna se presenta como defensa y promoción de la vida de los ciudadanos. Ningún otro título debe ser necesario, más que la posesión de la vida, el nacimiento, para convertirse en sujeto de derechos, que son proclamados como 'derechos del hombre'. Pero en realidad dichos derechos representan "la figura originaria de la inscripción de la nuda vida natural en el orden jurídico-político del Estado-nación» (Agamben, 2001, 25). Por medio de la proclamación de los derechos del hombre la nuda vida se convierte objeto inmediato del ejercicio del poder soberano. Así, lo característico de los Estados modernos será la creciente tendencia de lo político a apoderarse de la unuda vidan, que ha de ser producida para tal finalidad.

El poder es antes que nada poder sobre la vida y encuentra su realización en las relaciones de dominación en cuanto relaciones de inclusión y exclusión. Qué individuos y qué aspectos de la vida quedan protegidos por el mundo del derecho y cuáles y en qué grado son expulsados del mismo se convierte en expresión misma del ejercicio del poder. ${ }^{5}$ En el extremo se encuentra la absoluta desprotección, la reducción de los seres humanos a "nuda vida" carente de valor jurídicamente garantizado y políticamente protegido, pero existen múltiples formas de dosificar la muerte exponiendo a riesgos vitales extremos, vulnerabilizando y fragilizando a determinados sujetos, estableciendo espacios de marginalidad extrema destinada a individuos que supuestamente dañan la bonanza y el crecimiento de la comunidad politica. Agamben sostiene que regla (orden jurídico de los derechos) y excepción (suspensión de los derechos) se exigen y explican mutuamente (Agamben, 1999, 30s), porque lo decisivo del poder es la capacidad de decidir sobre lo que entra en un ámbito y otro. La reducción extrema a puro cuerpo que se opera en los campos de concentración y convierte a los individuos en objetos de decisiones arbitrarias del poder carentes de todo derecho actúa de manera latente en las formas de biopolítica moderna, formas evidentemente más suaves de administración y explotación de la vida, que no pretenden tanto aniquilar y doblegar, cuanto disciplinar, regular, controlar, estimular, etc. en relación a funcionalizaciones calculadas.

Sin embargo, el poder político entendido como bio-poder, como poder sobre la nuda vida, no es una entidad metafísica. Como hemos descrito más arriba, frente al relato político de la "ciudadania», no sólo resulta problemático el concepto de representación que establece una correlación entre la soberanía del pueblo y la soberanía del Estado, sino que esta última está trufada de intereses privados exteriores al sistema de representación, pero con poder político. La formas de administración y explotación de la vida, asi como su protección bajo la figura jurídica de los derechos ciudadanos o la suspensión de éstos bajo las diferentes formas de excepcionalidad o, simplemente, de no cumplimiento de los deberes supuestamente contraídos por el Estado frente a los ciudadanos (en realidad conquistados duramente por éstos), dependen de la correlación de fuerzas políticas.

"Hoy, cuando la concentración de poder productivo, tecnológico y cultural en manos de los nuevos entes orgánicos económicamente (fácticamente) dominantes es la mayor que ha conocido la humanidad, el débil y permeable formalismo de los derechos representativos de los "ciudadanos iguales", en el interior de cuyo sistema de relaciones ha sido posible la concentración de ese poder, viene a ser cera maleable entre sus manos" (Capella, 1993, 133).

\section{Ciudadanía e inmigración}

En este horizonte general de una ciudadania fragmentaria, limitada e ilusoria (Martínez de Pisón, 2003, 79), los inmigrantes concentran sobre si y de una manera agudizada dos dilemas fundamentales del concepto y la realidad de la ciudadanía en el marco del capital-parlamentarismo: por un lado, el dilema que se deriva de la identificación entre ciudadanía y nacionalidad $y$, por otro, el que procede de la creciente confrontación de la lógica del mercado con la lógica de los derechos. ${ }^{6}$

La construcción en Occidente de una sociedad civil en la que quedara superado el carácter determinante de las relaciones primarias y se establecieran procedimientos abstractos de asignación de las posiciones sociales y de distribución de los bienes económicos, sociales, políticos y culturales, el establecimiento de esta forma especial de socialización ha estado indisolublemente unida al problema del establecimiento de las fronteras de la comunidad política para la que tienen validez dichos procedimientos, asi como al problema de la asimetría y la desigualdad real que sobrevivían y se perpetuaban a través suyo. Como hemos visto, el dilema de la cultura política moderna nace de la contradicción entre una lógica interna que apunta a la universalización igualitaria y una praxis que delimita 
el ámbito de validez a la comunidad nacional y establece formas de integración discriminadora de sujetos aceptados en el territorio, pero excluidos de la ciudadanía plena, o que poseyendo una titularidad formal de ciudadanía, ven negada o mermada la ciudadanía sustantiva (López Sala, 2002, 97). ${ }^{7}$

La conexión entre nacimiento, territorio y Estado, que constituye la base de la soberanía moderna desde la declaración de los Derechos del Hombre de 1789, es cuestionada permanentemente por la presencia de los inmigrantes, que pone de relieve los límites de esa conexión, una conexión que sólo puede ser mantenida por medio de un control cada vez más riguroso y violento de los movimientos espaciales, que contrasta enormemente con la liberalización operada en relación a la circulación de capitales, tecnología, información, etc. (de Lucas, 2004a, 363ss). Los inmigrantes y refugiados sacan a la luz con su sola presencia en el territorio acotado del Estado tanto la diferencia entre nacimiento y nación, como el fundamento "secreto" de la biopolítica: la nuda vida, expuesta permanentemente a la amenaza de ser desposeida de todo derecho. En relación a los inmigrantes y refugiados se puede apreciar claramente cómo el Estado convierte la nuda vida, algo que cualquiera posee, también ellos, en algo diferente, que ya no posee cualquiera, la vida especifica de los ciudadanos. Resulta asimismo apreciable que para esa conversión limitadora no existe ninguna justificación razonable, que la línea que separa a los "meros" seres humanos de los ciudadanos puede desplazarse y que exclusión e inclusión pueden afectar alternativamente a determinados sujetos dependiendo de las constelaciones de poder. ${ }^{8}$

Si bien intuitivamente percibimos al inmigrante como ser humano, persona como nosotros, existen un conjunto de categorias ("extracomunitario", "clandestino", uirregular») que lo despojan de esa condición y lo estigmatizan negativamente como no ciudadano, como no europeo, como no nativo, etc. Los mecanismos sociales, políticos y juridicos que lo excluyen del reconocimiento de ciudadanía convierten simultáneamente a quien es objeto de esa exclusión en uno-persona". Por eso los derechos humanos, basados en el reconocimiento de una supuesta universalidad de la persona, no pasan de ser una declaración de principios, porque de hecho ser persona es una variable de la condición social. La desigualdad de trato a los nativos y los inmigrados, "en virtud de la cual algunos extranjeros son excluidos de los derechos civiles fundamentales, es potencialmente la puesta en marcha de un proceso de reducción de ciertas categorias de seres humanos de personas a no-personas» (Dal Lago, 2000, 139).
Contra esta afirmación parece hablar el hecho de que muchos paises receptores de inmigración hayan concedido determinados derechos civiles o sociales a los extranjeros residentes legales, aunque no posean el titulo de ciudadanía y el conjunto de derechos reservados a los nacionales, si bien dicha concesión y el tiempo de residencia exigido para la misma varía de un pais a otro (Zincone, 2004, 239ss). Incluso los inmigrantes no regularizados reciben de hecho, pese a las legislaciones cada vez más restrictivas, prestaciones educativas y sanitarias o de otro tipo. Podria pensarse que el reconocimiento de los derechos humanos no necesariamente ha de estar unido al estatuto de ciudadanía, al menos mientras que éste se mantenga vinculado al título de nacionalidad. Los inmigrantes podrían poseer no sólo derechos civiles, económicos, sociales y culturales, sino también en determinadas condiciones todos los derechos políticos, bastaría vincularlos a la residencia y no a la ciudadanía-nacionalidad (de Lucas, 2004b, 225ss). El problema es que $\sin$ un replanteamiento de la propia ciudadanía, los derechos, amenazados permanentemente por la lógica del poder y del mercado, quedan a merced de los vaivenes de las politicas de inmigración, y hoy no corren vientos demasiado favorables. ${ }^{9}$ De mantenerse el vínculo entre ciudadanía y nacionalidad los inmigrantes siempre dependerán de una protección externa ofrecida desde una soberanía a la que no se pertenece y que puede cancelar en cualquier momento el ofrecimiento. Sin embargo, los Estados-nación no prevén ninguna otra posibilidad de alcanzar el estatuto de ciudadanía que el de la "naturalización", vía escasamente transitable. Esto es lo que ha llevado a alguno a abogar por una "ciudadanía trasnacional" que admita una pluralidad de pertenencias nacionales (Bauböck, 2004, 195ss). En cierto modo, la ciudadanía de la Unión Europea podría ser un referente de ciudadania trasnacional, en la que a largo plazo los residentes provenientes de terceros paises podian ser incluidos ${ }^{10}$, pero nada apunta en esa dirección en el nuevo Tratado Constitucional de la Unión Europea (Aguelo y Chueca, 2005).

¿Cuáles son los obstáculos que no sólo impiden avanzar en esa línea, sino que provocan retrocesos evidentes en la vinculación entre la ciudadanía como pertenencia a un Estado y la ciudadanía como dotación de derechos? Para responder a esta cuestión quizás sea necesario lleva a cabo un vuelco de perspectiva: mientras que en los años de la posguerra la ciudadanía y su dotación de derechos (sociales) podía aparecer como un antídoto de las desigualdades producidas por el capitalismo (Marshall, 1992), en estos momentos más

ARBOR CLXXXI 713 MAYO-JUNIO [2005] 53-66 ISSN: 0210-1963 
bien es el capitalismo el que actúa como un «antídoto contra la ciudadanía» (Zincone, 2004, 238).

El triunfo de las políticas económicas neoliberales ha acelerado en los países más ricos la tendencia a la segmentación de la fuerza de trabajo con múltiples manifestaciones: el desempleo, la subproletarización de una parte de la mano de obra con una relación sólo esporádica con el mercado de trabajo, la precarización de una parte importante del empleo debida, por un lado, a la creciente externalización empresarial de las actividades a través de la proliferación de sistemas de subcontratación bajo control centralizado y con acaparamiento de los beneficios por los grandes grupos empresariales y, por otro, a la flexibilización y el crecimiento de la temporalidad, la pérdida de capacidad negociadora de los trabajadores, la dualización y polarización del escalafón profesional, con un nivel directivo y de gestión perceptor de ingresos de lujo y unos nivel inferiores que ven disminuir desde hace décadas su participación en la apropiación de los beneficios, etc. (Díaz-Salazar, 2003; Alonso, 1999; Castel, 1997).

Es más, en ciertos sectores productivos hemos asistimos en los últimos años a un crecimiento de la economía sumergida: en la agricultura, la hostelería-restauración y los servicios menos cualificados (limpieza, servicio doméstico, etc.) la incidencia de la economía sumergida es muy elevada. España es uno de los países de la Unión Europea con más economía oculta. Y no cabe duda de que entre ésta y el empleo degradado existe una relación de mutua implicación. La irregularidad lleva consigo la desprotección jurídica, social y sindical de los trabajadores. Dada esta situación del mercado de trabajo, la inserción laboral de la mayoria de los inmigrantes se viene produciendo en las ramas económicas con más incidencia de la economía sumergida y en los segmentos de empleo más precarios y descualificados, con mayor grado de irregularidad y más desprotegidos. Si existe una tendencia general a la precarización del empleo puede decirse que los inmigrantes representan la avanzadilla de dicha precarización. Y lo mismo cabe indicar respecto del desempleo, que los inmigrantes sufren con mayor intensidad.

La politica migratoria está estrechamente unida a la política económica y al fenómeno de la economía llamada informal, lo que queda patente en el desequilibro resultante del diferente peso administrativo de los controles fronterizos respecto a las inspecciones de los lugares de trabajo o de las medidas de expulsión de los trabajadores extranjeros «irregulares» respecto a las sanciones a los empresarios que infringen la ley. El control basado en la exteriorización y criminalización de los inmigrantes como trabajadores «ilegales» es un instrumento clave del Estado en el proceso estructural de expansión y transformación del sistema capitalista mundial. Podría hablarse incluso de una "funcionalidad" económica de la "ilegalidad", pues la "irregularidad" de los inmigrados facilita su sobreexplotación, reduce los costes de contratación, fragiliza su posición negociadora frente al patrón y debilita sus posibilidades de oposición a condiciones laborales draconianas e injustas, ahorra costos estatales -a pesar de que los inmigrantes contribuyan a las arcas del Estado al menos con los impuestos indirectos-, dificulta sus posibilidades de organización y reivindicación, etc.

La vinculación entre permisos de trabajo y de residencia, así como el tipo de vigencia temporal de los mismos, por un lado, y la política de cupos que orienta la fuerza de trabajo inmigrante hacia ocupaciones especificas del mercado laboral (fundamentalmente agricultura, servicio doméstico y construcción) con un índice mayor de irregularidad y precariedad, por otro, ha creado un círculo vicioso de inestabilidad laboral y juridica, que aumenta considerablemente la vulnerabilidad y la discriminación de los inmigrantes en el mercado de trabajo (Alegre Canosa, 2002, 387). De hecho se han creado unos nichos laborales en sectores económicos y tipos de actividad con una presencia destacada de determinados colectivos inmigrantes no comunitarios. Este fenómeno lo ha calificado I. Wallerstein de uetnización del mercado laboral». Su funcionalidad económica está clara: la pertenencia al grupo social sirve para "hacer posibles unos salarios muy bajos para sectores enteros de la fuerza de trabajo" (Wallerstein, 1991, 58).

Además de la discriminación que supone una asignación de los inmigrantes a sectores y actividades con un índice mayor de irregularidad y precariedad, la posición que ocupan los inmigrantes laborales dentro de los respectivos mercados de trabajo, en gran medida condicionada por el tipo de acceso a los mismos, es peor de modo sistemático. En el caso de la agricultura, esto supone una inserción casi exclusiva en la modalidad eventual de trabajo, junto a enormes dificultades para la efectiva integración social debidas a la estacionalidad (cambio frecuente de zonas de trabajo, alojamiento en infraviviendas, imposibilidad de reunificación familiar, etc.). En el caso del servicio doméstico hemos visto renacer el empleo como "internas» de mujeres inmigrantes, lo que conlleva frecuentemente condiciones de explotación extrema, 
tanto por los horarios de trabajo, el grado de informalización y los salarios inferiores, como por la dependencia casi total respecto de las familias que las contratan. En la construcción se observa un predominio de la ocupación de los inmigrantes en la categoria de peón no cualificado. Sufren en mucha mayor proporción que los autóctonos la privación de derechos laborales como pagas extra, vacaciones pagadas, etc.

Podriamos decir que el trato que se da a los inmigrantes representa un paradigma extremo de la supeditación de la lógica ciudadana de los derechos a la lógica del mercado. Antes que ser vistos como sujetos de derechos son vistos como mera fuerza de trabajo, que el mercado demanda en condiciones de vulnerabilidad, precariedad, debilidad política, etc. y el Estado, pretendidamente o no, pero sí congruentemente, contribuye a producirla. De ahi la necesidad de percibir con claridad qué es lo que está realmente en juego en las políticas de inmigración, y no sólo para los inmigrantes (Zincone, 2004, 256).

\section{Políticas de inmigración y estado de excepción}

Las politicas migratorias vigentes en España declaran perseguir un doble objetivo: por un lado, la integración de los inmigrantes y, por otro, la persecución de la inmigración ilegal. ${ }^{11}$ Independientemente de las posibles interferencias entre ambos objetivos, cuando no de su carácter antitético, sobre todo si tenemos en cuenta que los actuales inmigrantes "regularizados» en su inmensa mayoria, al menos en España, han pasado por periodos más o menos largos de "no regularidad", es decir, que se persigue primero a los que luego se desea integrar; independientemente de estas posibles contradicciones, el doble objetivo señalado hace que las políticas migratorias estén presididas por la tendencia a la separación radical del tratamiento del inmigrante regular e irregular.

Es importante no olvidar al respecto que las politicas migratorias no son respuestas articuladas por los poderes públicos a fenómenos preexistentes claramente definidos, sino que ellas mismas ordenan, conforman y definen el fenómeno. En este sentido podemos decir que la migración es una construcción social en la que adquieren gran importancia las clasificaciones, las diferenciaciones y las divisiones que establecen los poderes públicos. Las políticas públicas en cuanto tecnologias de gobierno producen nuevas categorias de sujetos y las categorizaciones están orientadas hacia la producción de efectos sociales (Gil Araújo, 2002, 153). El doble objetivo mencionado más arriba ha conducido a la construcción de un doble sujeto: el inmigrante bueno/auténtico y el inmigrante inauténtico/sospechoso. Esta producción doble constituye el marco en el que los inmigrantes pueden formular ciertas demandas (políticas, socioeconómicas, culturales, etc.) y el Estado reconoce o rechaza dichas demandas (J. de Lucas, 2003, 27).

Aunque la línea que divide inmigrantes regularizados y sin papeles es más tenue de lo que parece y son múltiples los poros que la traspasan ${ }^{12}$, quisiera fijarme en este momento en la construcción del inmigrante "inauténtico», ya que es una clave fundamental de la ley de extranjería y sus sucesivas reformas $y$, además, permite mostrar en toda su crudeza la excepcionalidad que amenaza la lógica de los derechos ciudadanos.

Independientemente de su éxito o fracaso, las políticas desarrolladas para combatir la llamada inmigración "ilegal», los medios económicos, administrativos y policiales destinados al control de fronteras y al rechazo de los inmigrantes "ilegales", son considerablemente superiores a los esfuerzos destinados al otro supuesto objetivo de las políticas de inmigración: la integración. Para comprobarlo bastaría comparar las inversiones que el Estado dedica al "Servicio Integrado de Vigilancia Exteriorn, tanto inversiones en tecnología e infraestructura para el control de fronteras, como gastos de personal que supone su sostenimiento, con la infradotación de las políticas de integración de Comunidades Autónomas y Ayuntamientos. ${ }^{13}$

También la evolución de la legislación en materia de extranjeria presenta un desequilibrio semejante. La LO 8/2000 no sólo ha supuesto un debilitamiento del principio general de equiparación entre españoles y extranjeros con residencia legal hacia la que tendia la LO $4 / 2000$, también ha introducido restricciones importantes en el reconocimiento de derechos a los inmigrantes en situación irregular: se les excluye del ejercicio de derechos fundamentales como el de libertad de reunión y manifestación, la libertad de asociación, el derecho al trabajo y la seguridad social, la libertad de sindicación y el derecho a huelga, el derecho a la asistencia juridica gratuita, etc. Es decir, se agranda el abismo entre regularizados e "ilegales». Al mismo tiempo se dificulta considerablemente la obtención de residencia regular y se dota de una mayor severidad al régimen sancionador (Diéz Bueso, 2000; Aguelo, 2002). ${ }^{14}$ La LO 14/2003, 
aprobada con los votos del PP y el PSOE, parece orientada casi de modo exclusivo al control de los flujos, con la clara intención de reducirlos completamente e impedir el tránsito de la irregularidad a la regularidad (acceso policial al padrón municipal, normas de procedimiento administrativo especiales para extranjeros segregados del procedimiento común, endurecimiento del sistema sancionador en relación a expulsiones y devoluciones, aumento considerable de las dificultades para la reagrupación familiar, transferencia de obligaciones de control fronterizo a las compañias privadas de transporte, etc.). El resultado más evidente de esta legislación en materia de extranjería es la creación de un sistema dual de ciudadanía (Silveira, 2003,68) y un régimen administrativo especial por razón de nacionalidad (Aguelo, 2004, 91). Los extranjeros provenientes de los llamados "terceros países" quedan excluidos parcial o totalmente del contrato de ciudadanía y sometidos a un contrato de extranjería, caracterizado por la provisionalidad, la parcialidad y la superficialidad y supeditado a la necesidades laborales o demográficas del país de acogida (de Lucas, 2002, 79). Quienes ni siquiera alcanzan este estatuto, han de vivir bajo la amenaza permanente de expulsión, al margen de toda protección legal y social, o pasando a engrosar el número creciente de los «inexpulsables» (unos 10.000 anualmente).

Esta política migratoria claramente restrictiva, fundamentalmente orientada al control policial de los flujos y a combatir la inmigración llamada «ilegal" se justifica por la supuesta situación de emergencia en que vive España y Europa. Si hacemos caso a las declaraciones de los gobiernos y a los titulares de ciertos medios de comunicación, ambas se encuentran sometidas a una presión migratoria sin precedentes, que desborda todas las posibilidades razonables de integración de los inmigrantes. Los términos "invasión", "avalancha", "oleada", "riada", etc., provenientes de la descripción de catástrofes naturales y usados con machacona insistencia, son eficaces transmisores de esa forma de percibir la inmigración, destinada a asegurar el respaldo social a las políticas restrictivas supuestamente dirigidas a contener y limitar los flujos migratorios, aunque de facto sean uno de los factores principales en la producción de lo que en el lenguaje administrativo y mediático se denomina ula bolsa de inmigración ilegaln, de cuya funcionalidad económica no se puede dudar razonablemente. ${ }^{15}$

La producción social de la emergencia ha sido un recurso habitual de la política moderna de cara a la intensificación del control social y la legitimación de medios excepcionales creados para afrontarla. Para poder funcionar, dicha producción necesita generar un cierto clima de pánico difuso frente a un fenómeno presentado como peligroso y potencialmente destructivo, asi como la percepción de un determinado grupo social como enemigo. Esto ocurre hoy de modo paradigmático con la inmigración. La lucha contra la inmigración llamada uilegal» y la retórica de la emergencia son responsables de la construcción del objeto sobre el que se aplican las medidas excepcionales, medidas cuya vigencia sobrevive por lo general a la supuesta situación de emergencia que las justifica (Martínez de Pisón, 2003, 89s).

Los factores que intervienen en los cambios que afectan actualmente a los flujos migratorios: el proceso de globalización y la situación económica o política de los países de procedencia, las transformaciones del mercado de trabajo en los paises desarrollados, la flexibilización del proceso productivo, etc., todos estos factores son expulsados en los discursos politicos y mediáticos del ámbito de la responsabilidad política directa y atribuidos bien a la inflexible lógica económica, bien a la falta de cultura democrática de los paises de origen, mientras que se focaliza la atención y la ejecución de medidas urgentes en la circulación de no-comunitarios en la Unión Europea y en los riesgos supuestamente asociados a dicha circulación: terrorismo, tráfico de drogas, redes de prostitución y mafias diversas. Todos aquellos problemas frente a los que las politicas vigentes revelan una incapacidad estructural manifiesta (precariedad del empleo, paro, vivienda, demografia, diferencias norte-sur) encuentran en la figura políticamente construida del inmigrante uilegal» un referente sustitutorio sobre el que aplicar las medidas excepcionales que legitiman a los mismos poderes que las aplican.

Que el emigrante llamado "ilegal" se haya convertido en sujeto escogido del discurso de la emergencia, así como de la legislación y las medidas políticas de excepción tiene que ver, como hemos visto, con que su presencia pone en entredicho las bases mismas del Estado-nación. Dado que la ficción de la soberanía moderna, en la que el ser humano y el ciudadano, nacimiento y nación, se identifican, queda trastornada con la aparición de los inmigrantes, no resulta aventurado poner en relación dicho trastorno con los intentos más diversos por mantener fuera al otro llevados a cabo por las instituciones que representan 0 detentan la soberanía como ejercicio del biopoder. Los centros de internamiento para extranjeros, verdaderos agujeros negros del Estado de Derecho, los invernaderos de plástico, donde los inmigrantes son degradados a meros 
cuerpos esclavizados por la agroindustria, los miles de prostibulos, en los que las inmigrantes son retenidas y explotadas sexualmente,... son lugares todos donde la reducción de seres humanos a mero cuerpo revela la significación biopolítica de las políticas de inmigración.

Esto vale en primer lugar para las fronteras que sirven de línea divisoria entre la riqueza y la pobreza y que se han convertido en verdaderas zonas de muerte, zonas en la que la vida de los que intentan traspasarlas no vale nada. Muchos de los inmigrantes clandestinos, de los "espaldas mojadas" que intentan entrar en EEUU cruzando un desierto de muerte, de los africanos que se aventuran en pateras mortales a cruzar el estrecho, de los subsaharianos que han de superar un inmenso mar de arena antes de llegar a la frontera con Europa, muchos de estos inmigrantes perecen en el intento.

Los cementerios de las localidades españolas que jalonan la línea divisoria entre la riqueza y la pobreza están plagados de nichos anónimos. Escupidos por el mar a las orillas de un territorio que soñaron cargado de riquezas materiales y promesas de futuro, no son más que cuerpos inertes sin identidad, sin nadie que los reclame, sin nadie que los vele. Estos cuerpos sin nombre y sin vida representan el caso extremo de un destino fatal preparado por las sociedades opulentas a quienes carecen del marchamo nacional, a quienes no poseen el salvoconducto azaroso y providente que otorga la nación. Ellos testifican en su mudez la tenue línea que separa la reducción a «nuda vida» de su aniquilación.

A aquellos para los que el intento de traspasar la frontera no acaba en muerte o no son apresados y devueltos en el mismo instante, les espera una existencia espectral de "seres invisibles", cuerpos explotables sin documentación que les garantice unos derechos mínimos. Serán tolerados, explotados y permanentemente amenazados al mismo tiempo. Como hemos visto, cada día resulta más difícil alcanzar el estatuto legal de "residente" que los mismos paises receptores de inmigración prevén en su legislación. Las leyes de extranjeria condenan a los "sin-papeles» a una situación de carencia de la mayoria de derechos fundamentales y de amenaza de expulsión por procedimiento "preferente", lo que en realidad supone estar condenados a ser "carne de cañón" de la economia irregular.

Los Centros de Internamiento de Extranjeros representan de modo singular ese estado de excepcionalidad al que se ven reducidos los «sin-papeles». Son centros que han aparecido en toda Europa para internar a inmigrantes que han recibido una orden de expulsión y están a la espera de su retorno. No son centros penitenciarios y los que son privados de libertad en ellos no han cometido delito alguno. La finalidad declarada de los mismos es meramente preventiva y cautelar. Se trata de una retención temporal mientras se sustancia un expediente administrativo de expulsión. En principio, al extranjero sin papeles sometido al procedimiento de expulsión se le concede la posibilidad de alegar en el plazo de cuarenta y ocho horas, pero la administración no tiene que esperar a la resolución de dicha alegación para la ejecución de la expulsión, con lo que se produce una situación de indefensión y de ausencia de tutela judicial efectiva (Silveira, 2002). Con todo, como en muchos casos resulta imposible averiguar el pais de procedencia del inmigrante 0 no existe convenio de repatriación con el mismo, se le entrega una orden de expulsión y se le pone en libertad, con lo que en realidad más que del país se le expulsa del sistema de garantías jurídicas y se le coloca en una situación de total desamparo legal. Podría decirse que estas instituciones actúan de facto como "creadoras de extranjeros a-legales y marginales" (Silveira, 2002, 94).

Las analogias con la figura del homo sacer analizada por G. Agamben resultan patentes: "Si los sujetos ya han sido expulsados, no son, para decirlo de alguna manera, existentes en el territorio del Estado desde el punto de vista jurídico. La situación de excepción que se crea es que las personas detenidas en esos centros no tienen asignado ningún estatuto jurídico. Es como si su existencia física hubiese sido separada de su estatuto juridicon (Agamben, en: Link, 2001). La existencia de los centros de internamiento para extranjeros revela la esencia biopolítica del control de los flujos migratorios.

¿Cómo inscribir esta situación en el marco de lo que el discurso político de la modernidad Ilama Estado de Derecho? Quizás ayuden a responder a esta cuestión los argumentos de Giorgio Agamben sobre la relación entre soberanía, estado de excepción y campo de concentración y su vigencia en los Estados denominados democráticos (Agamben, 2004, 11ss). Su interés se centra en el análisis de lo político a la vista de la crisis actual de su representación, es decir, a la vista de ese nuevo espacio politico que se abre cuando el sistema político del Estado-nación entra en crisis. Lo que investiga es justo la nueva forma de funcionar el poder e intenta formular teóricamente una redefinición de las relaciones entre soberanía y territorio.

DRROR CIXXXI 713 MAYO-JUNIO [2005] 53-66 ISSN: 0210-1963 
La estructura del Estado-nación existente hasta ahora, fundada en la conexión funcional de tres elementos -el orden jurídico del Estado, el territorio correspondiente y la pertenencia de los ciudadanos a cada nación- se encuentra en proceso de disolución. A partir de la investigación de ese proceso, Agamben desarrolla un modelo de poder que busca unir tanto el modelo juridico-institucional, es decir, una concepción de soberanía y Estado, como el modelo biopolítico de poder, es decir, de displinamiento de los cuerpos. El estado de excepción, en cuanto dimensión jurídico-abstracta, necesita de un lugar en que concretarse: para Agamben ese lugar es el campo de concentración. La suspensión del orden que se produce en el campo ha pasado, según él, de ser una medida provisional frente a la emergencia a convertirse en una técnica permanente de gobierno.

Sin embargo, resulta llamativo que en la concepción de Agamben no tenga ningún papel relevante el trabajo. Precisamente la aplicación de los conceptos de homo sacery de uestado de excepción" al fenómeno de la inmigración exige, sin embargo, reconocer los centros de internamiento, las legislaciones y politicas de excepcionalidad, la criminalización de la inmigración sin papeles, etc. como la otra cara de la nueva flexibilidad del capitalismo, es decir, como metáforas del control despótico sobre la movilidad de la fuerza de trabajo. Los centros de internamiento son una pieza del sistema de explotación del capitalismo globalizado sobre los movimientos migratorios (Mezzadra, 2005). La infraestratificación del mercado de trabajo por medio de los y las inmigrantes, sobre quienes recaen, gracias a las legislaciones y políticas de excepcionalidad, la máxima precarización y vulnerabilización como trabajadores y trabajadoras, es una estrategia de dominación que tiene que ver con el sistema productivo y la lucha de clases nunca del todo pacificada.

Es necesario, pues, prestar atención a nuevas luchas que protagonizan los inmigrantes, en primera línea por su legalización, luchas que ponen de manifiesto su resistencia y oposición a los esfuerzos de control de los Estados desarroIlados: En este sentido, la inmigración no es meramente un efecto funcional de los desequilibrios del mercado de trabajo en los paises receptores, sino también un movimiento de sujetos sociales que el poder intenta controlar e integrar, pero que se resisten y luchan contra ese control. La reconfiguración permanente y el desarrollo continuado de prácticas estatales de sometimiento, el compromiso que se restablece continuamente de manera cambiante con los subordinados, la formación de nuevas coaliciones, etc., ese movimiento se mantiene en su dinámica a partir de los movimientos de resistencia y lucha. En este sentido dichos movimientos no existen sin las políticas de control, cuyo caso extremo es el campo de concentración convertido por Agamben en paradigma de la política moderna, pero las luchas de los usin papeles" muestran la necesidad de ver las migraciones como un fenómeno en el que se actualizan las resistencias frente a la dominación. 
1 No podemos entrar aqui en la debatida cuestión de si el discurso de los derechos tiene realmente por sí mismo el poder que se le atribuye, aunque no puede negarse su valor en la reacción y sublevación de los sujetos y grupos sociales que experimentan la injusticia. Remitimos para esta cuestión a Brown, Williams y Jaramillo (2003).

2 No puedo entrar aqui a discutir las posibilidades y dificultades de una ciudadanía cosmopolita, ver para ello una estupenda sintesis en Velasco, 2003; también García Inda, 2003b.

3 Según la Constitución revolucionaria de 1793, por la que se define la condición de ciudadano francés, bastaba con ser adulto y haber vivido en Francia durante un año para que un extranjero obtuviera derecho de permanencia en el pais y los demás derechos activos de ciudadano (cf. J.A. Coleman, 1995, 78).

4 Aquí no interesa tanto dirimir las controversias existentes en torno al verdadero carácter de las naciones, por ejemplo, hasta qué punto son "comunidades inventadas" (B. Anderson, 1983), uinvenciones históricas arbitrarias" (E. Gellner, 1997) o son construcciones históricas que necesitan "factores primarios" no inducibles; si están vinculadas al surgimiento del Estado-nación o son independiente de él, etc. (M. Castells, 1998, 50ss). Lo que interesa aquí es la cuestión de por qué los Estados de derecho modernos, que han ejercido un papel de referente modernizador bastante universal, se vinculan a la idea de nación y qué papel juega dicha idea en su constitución, y esto con vistas a clarificar el concepto de identidad moderna como "ciudadania".

5 Que este ejercicio del poder esté regulado democráticamente no impide que se ejerza como poder que establece la línea divisoria entre dentro y fuera. La diferencia entre demos y población, tan antigua como la misma democracia, permite utilizar la categoría del demos upara legitimar el hecho de que los que están dentro de él puedan obligar a los que están fuera que obedezcan sus leyes y decisiones» (Zapata, 2003,119).
6 Frecuentemente estos dilemas son articulados en la teoria politica actual como dilema entre democracia y «multiculturalismos». No puedo entrar aqui en el análisis y la critica del proceso ideológico de "culturización» de la exclusión, tal como ha sido llevado a cabo por autores como Sartori (2002) o Azurmendi $(2001 ; 2003)$. Ver al respecto Zamora, 2003, 223ss. Evidentemente hablar de proceso uideológico" no significa que la construcción social del «extrañon no sea un instrumento poderosisimo de discriminación social, económica y politica, significa más bien que las diferencias étnico-culturales se reifican para explicar $y_{\text {, a fortiori, }}$ legitimar la discriminación. Como Señala J. de Lucas, "la mayor parte de los conflictos que se presentan como identitarios pueden resolverse en conflictos de intereses acerca de la distribución de la riqueza y de la participación en el poder y de las condiciones para esa participación y distribución" $(2001,99)$. Sobre inmigración e interculturalidad han corrido ríos de tinta. Para una aproximación comprensiva del tema ver Zapata-Barrero, 2004.

7 La distinción entre "ciudadanía formal» y "ciudadania sustantiva" resulta fructífera para abordar los dilemas de la ciudadania en el capital-parlamentarismo siempre que no se considere que ha existido en algún momento una plena identificación real entre las dos y que es la inmigración la que cuestiona dicha identificación al incorporar al territorio del Estado-nación poblaciones excluidas total o parcialmente de ambas, sea por la proliferación de estatus de pertenencia, sea por la dosificación de derechos relativa a dicha proliferación. Como he intentado exponer en el primer apartado, la relación entre ciudadanía formal y ciudadania sustantiva siempre a sido problemática y, para sectores importantes de población, ciertamente precaria. En este sentido no sólo es importante qué derechos poseen los ciudadanos, sino cómo los poseen, es decir, de qué manera se hacen efectivos.
8 Como ha señalado Agamben, Europa ha conocido después de la I Guerra Mundial en diferentes Estados procesos más o menos masivos de desnaturalización o desnacionalización de sus propios ciudadanos, lo que muestra que el estatus de ciudadania puede perderse (Agamben, 2001, 23). Pero no hace falta la pérdida del estatus de ciudadanía para que se vea recortado de modo importante para partes significativas de la población el contenido del mismo, tal como muestra la evolución de las politicas redistributivas y sociales de los llamados Estados del Bienestar desde mediados de los años setenta del pasado siglo.

9 Hemos podido ver como se despoja a los residentes legales de derechos anteriormente concedidos (Reforma de la Asistencia Social en EEUU) o se alargan los periodos de residencia para tener acceso a los mismos (Australia) (Bauböck, 2004, 181, nota 4). Las últimas reformas legales en materia de extranjería en Austria, Alemania, España, etc. no caminan, como veremos, en la dirección de ampliar el espectro de derechos y de facilitar el acceso a los mismos, sino más bien en sentido contrario. Esto pone de manifiesto que "la ampliación de la ciudadanía como dotación a los extranjeros no es un proceso lineal, y en algunos casos se ha retrocedido mucho" (Zincone, 2004, 243).

10 Esta ciudadanía se está construyendo de facto sobre la exclusión de la inmigración y la producción de una nueva clase de "metecos" (Silveira, 1998; J. de Lucas, 2001. Martinez de Pisón, 2003, 86ss).

11 La conexión entre integración de los inmigrantes y lucha contra la inmigración llamada ilegal está planteada desde el Plan Interministerial para Integración Social de los Inmigrantes elaborado por el Ministerio de Asuntos Sociales en 1994, plan que impulsó la creación del Foro para Integración Social de los Inmigrantes y el Observatorio Permanente de la Inmigración. Como ha señalado Gil Araújo, es significativo que el Programa GRECO se presente como Programa de integración y que gran parte del documento se dedique a detallar las medidas para mejorar el control de las fronteras exteriores (Gil Araújo, 2002, 171). 
12 Los Estados desarrollados han llevado a cabo un conjunto de reformas legislativas presididas por lo que J. de Lucas ha llamado "lógica del regateo" y que afecta a todos los inmigrantes, estableciendo una verdadera carrera de obstáculos con amenaza permanente de recaida en la «ilegalidad", reduciendo las garantias y aumentando la discrecionalidad de la Administración, promoviendo legalmente la discriminación laboral y la vulnerabilidad de los inmigrantes, etc. (de Lucas, 2004a, 371).

13 Ver el Informe sobre la inmigración clandestina durante el año 2004 (http://www.apdha.org/areas/documentos/inmigra2004.pdf).

14 Según Ángel G. Chueca Sancho, la actual Ley de Extranjería viola la Convención Europea de Derechos Humanos, los pactos de la ONU, la Convención de Derechos del Niño y el Convenio no 87 de la OIT, etc. (Chueca Sancho, 2002, 259).

15 Frente a esta vinculación suficientemente documentada (cf. Abad Márquez, 2002), el discurso dominante sigue presentando la inmigración clandestina como un fenómeno cuyas causas son exteriores, ya sea la testaruda voluntad de los inmigrantes de penetrar ilegalmente en el territorio nacional, la pasividad de los paises de origen, la actuación de las mafias o una combinación de todas ellas. La única causa interior que parece reconocerse es una supuesta tolerancia frente a los inmigrantes llamados uilegales", que se identifica como causa del "efecto llamada».
Abad Márquez, Luis V. (2002): "Trabajadores inmigrantes en las economias avanzadas. La paradoja de la demanda adicional en mercados con exceso de ofertan, en F.J. García Castaño/C. Muriel López: La inmigración en España. Contextos y Alternativas, Granada, Laboratorio de Estudios Interculturales (Univ. Granada), Vol. II, pp. 459-467.

Agamben, G. (1999): Homo sacer. El poder soberano y la nuda vida, Valencia, Pre-Textos.

Agamben, G. (2001): Medios sin fin. Notas sobre la politica, Valencia, Pre-Textos.

Agamben, G. (2004): Estado de excepción. Homo sacer II, 1, Valencia, Pre-Textos.

Aguelo, P. (2002): "Los derechos y libertades de los extranjeros: análisis crítico del marco jurídico español", en Centro Pignatelli (ed.): La inmigración, una realidad en España. Seminario de Investigación para la Paz, Zaragoza, Departamento de Cultura y Turismo, D.L., pp. 325-369.

Aguelo, P. (2004): "Derechos y libertades de los extranjeros"), en R. Lara y otros: La globalización y los derechos humanos. IV Jornadas Internacionales de Derechos Humanos (Sevilla, 2003), Madrid, Talasa, pp. 90-102.

Aguelo Navarro, P. - Chueca Sancho, Á. G. (2005): La constitución europea y... los extranjeros (www.intermigra.info).

Alegre Canosa, M. A. (2000): "Las políticas inmigratorias", en J. Adelantado (coord.): Cambios en el Estado del Bienestar. Politicas sociales y desigualdades en España, Barcelona, Icaria, p. 379-412.

Alonso, L. E. (1999): Trabajo y ciudadanía. Estudios sobre la crisis de la sociedad salarial. Madrid, Trotta.

Anderson, A. (1983): Imagined Communities: Reflections on the Origin and Spread of Nationalism, Nueva York, Verso.

Azurmendi, M. (2001): Estampas de El Ejido. Un reportaje sobre la integración del inmigrante, Madrid, Taurus.

Azurmendi, M. (2003): Todos somos nosotros, Madrid, Taurus.

Balibar, E. (1992): Les frontières de la démocratie, Paris, La Découverte.
Bauböck, R. (2004): "Cómo transforma la inmigración a la ciudadanía: perspectivas internacionales, multinacionales y transnacionales", en G. Aubarell y R. Zapara (eds.): Inmigración y procesos de cambio. Europa y el Mediterráneo en el contexto global, Barcelona, Icaria/IEMed, pp. 177-214.

Brown, W. - Williams, P. y Jaramillo, I.C. (2003): Crítica de los derechos, Bogotá, Siglo del Hombre Editores.

Capella, J. R. (1993): Los ciudadanos siervos, Madrid, Trotta.

Castel, R. (1997): La metamorfosis de la cuestión social. Una crónica del asalariado. Buenos Aires, Paidós.

Castells, M. (1998): La era de la información. Economía, sociedad y cultura. Vol. II. El poder de la identidad, Madrid, Alianza.

Coleman, J. A. (1995): «Una nación de ciudadanos", Concilium, n ${ }^{\circ} 262$, pp. 75-87.

Chueca Sancho, Ángel G. (2002): "Los derechos humanos de los extranjeros en Europa: entre el respeto y la discriminación", en Centro Pignatelli (ed.): La inmigración, una realidad en España. Seminario de Investigación para la Paz, Zaragoza, Departamento de Cultura y Turismo, D.L., pp. 237-261.

Dal Lago, J. A. (2000): "Personas y no personas» en H. C. Silveira Gorski (ed.): Identidades comunitarias y democracia, Madrid, Trotta, pp. 127-144.

Diaz-Salazar, R. (2003): Trabajadores precarios. El proletariado del siglo XXI. Madrid, Ed. HOAC.

Díez Bueso, L. (2000): „El régimen jurídico de la inmigración en España: contexto, texto y pretexto", en Documentación Social, no 121, pp. 161-182.

Foro I. Ellacuría (1999): La globalización y sus excluidos, Estella, EDV.

Garcia Inda, A. (2003a): "Ciudadania y cultura de los derechos: el 'ciudadano consumidor'", en Bernuz, M. J. y Susín, R. (coords.): Ciudadania. Dinámicas de pertenencia y exclusión, Logroño, Servicio de Publicaciones Univ. de la Rioja, pp. 59-74. 
Garcia Inda, A. (2003b): «El cosmopolitismo y la nuevas fronteras de la ciudadanian, en Martínez Pisón, J. y Giró, J. (Coords.): Inmigración y ciudadanía. Perspectivas sociojuridicas, Servicio de Publicaciones Univ. de la Rioja, pp. 91-111.

Gellner, E. (1997): Naciones y nacionalismos, Madrid, Alianza.

Gil Araújo, S. (2000): «Políticas públicas como tecnologías de gobierno. Las políticas de inmigrantes y las figuras de la inmigraciónn, en C. Clavijo y M. Aguirre (eds.): Políticas sociales y Estado del bienestar en España: las migraciones. Informe 2000. Madrid, Fundación Hogar del Empleado, pp. 147-190.

Izquierdo, A. (2001): «Epílogo. La política hacia dentro o el sistema de inmigración irregular en España", en: S. Sassen: ¿Perdiendo el control? La soberania en la era de la globalización, Barcelona, Edicions Bellaterra, pp. 107-139.

Link, D. (2001): «Un encuentro con Giorgo Agamben" (Entrevista), Weblslam, Núm. 137, 5 de septiembre.

López Sala, A. M. (2002): "Los retos políticos de la inmigración", en Isegoría, n० 26, pp. 85-105.

Lucas, J. de (2001): "Ciudadania y Unión Europea intercultural", en Anthropos, n० 191, pp. 93-116.

Lucas, J. de (2002): "La herida original de las politicas de inmigración. A propósito del lugar de los derechos humanos en las políticas de inmigración", en Isegoria, no 26 , pp. 59-84.

Lucas, J. de (2003): «Inmigración y globalización. Acerca de los presupuestos de una politica de inmigración", en Martínez Pisón, J. y Giró, J. (Coords.): Inmigración y ciudadanía. Perspectivas sociojurídicas, Logroño, Servicio de Publicaciones Univ. de la Rioja, pp. 23-52.

Lucas, J. de (2004a): "¿Cómo globalizar los derechos humanos? El test de la inmigración", en R. Lara y otros: La globalización y los derechos humanos. IV Jornadas Internacionales de Derechos Humanos (Sevilla, 2003), Madrid, Talasa, pp. 361-393.

Lucas, J. de (2004b): «Ciudadanía: la jaula de hierro para la integración de los inmigrantes", en G. Aubarell y R. Zapara (eds.): Inmigración y procesos de cambio. Europa y el Mediterráneo en el contexto global, Barcelona, Icaria/IEMed, pp. 215-236.
Marshall, T.H. (1992): Citizenship and Socia Class, $1^{a}$ ed. 1950, Londres, Pluto Press.

Martínez de Pisón, J. (2003): "Ciudadanía e inmigración", en Bernuz, M. J. y Susín, R. (coords.): Ciudadanía. Dinámicas de pertenencia y exclusión, Logroño, Servicio de Publicaciones Univ. de la Rioja, pp. 75-96.

Sartori, G. (2002): La sociedad multiétnica. Extranjeros e islámicos. Apéndice actualizado, Madrid, Taurus.

Sassen, S. (2001): ¿Perdiendo el control? La soberanía en la era de la globalización, Barcelona, Edicions Bellaterra.

Silveira Gorski, H. C. (1998): "La Unión Europea, los refugiados y los inmigrantes ilegales, sans papiers, clandestini...", en mientras tanto, $n^{\circ} 73$, pp. 43-54.

Silveira Gorski, H.C. (2002): "Los Centros de Internamiento de Extranjeros y el futuro del Estado de Derechon, mientras tanto, $n^{\circ} 83$, pp. 93-102.

Silveira Gorski, H.C. (2003): "Democracia, multiculturalidad y extranjerian, en J. A. Zamora (coord.): Ciudadanía, multiculturalidad e inmigración, Estella, Ed. Verbo Divino, pp. 59-71.

Velasco, D. (2003): "Ética y politicas para una ciudadania universalı, en J. A. Zamora (coord.): Ciudadania, multiculturalidad e inmigración, Estella, Ed. Verbo Divino, pp. 13-58.

Wallerstein, I. (1991): «Universalismo, racismo y sexismo, tensiones ideológicas del capitalismon, en E. Balibar y I. Wallerstein: Raza, nación y clase, Madrid, IEPALA, p. 49-62.

Zamora, J. A. (2003): «Inmigración, ciudadanía y multiculturalidad», en J. A. Zamora (coord.): Ciudadanía, multiculturalidad e inmigración, Estella, Edi. Verbo Divino, pp. 165-239.

Zapata-Barrero, R. (2000): «Inmigración e innovación polítican, en Revista Migraciones, $n^{\circ} 8$, pp. 7-58

.Zapata-Barrero, R. (2003): «Inmigración y multiculturalidad: hacia un nuevo concepto de ciudadanía", en Martínez Pisón, J. y Giró, J. (Coords.): Inmigración y ciudadania. Perspectivas sociojurídicas, Logroño, Servicio de Publicaciones Univ. de la Rioja, pp. 113-127.

Zapata-Barrero, R. (2004): Multiculturalidad e inmigración, Madrid, Editorial Sintesis.
Zincone, G. (2004): «Procesos migratorios y transformación de los derechos de ciudadanian, en G. Aubarell y R. Zapara (eds.): Inmigración y procesos de cambio. Europa y el Mediterráneo en el contexto global, Barcelona, Icaria/IEMed, pp. 237-259.

ARBOR CLXXXI 713 MAYO-JUNIO [2005] 53-66 ISSN: 0210-1963 